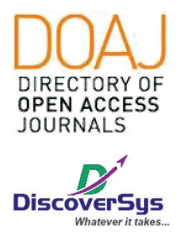

Published by DiscoverSys

\section{Gambaran prevalensi fraktur humerus di Rumah Sakit Umum Pusat (RSUP) Sanglah, Bali, Indonesia periode tahun 2015-2016}

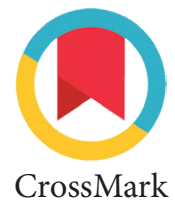

\author{
Ni Kadek Dyah Devita Sari, ${ }^{1 *}$ Anak Agung Gde Yuda Asmara ${ }^{2}$
}

\title{
ABSTRACT
}

Background: Fracture is the cause of a high number of disabilities worldwide. One of the fractures is humerus fracture, often occur because of injury. The classic symptoms of a fracture are a history of trauma, pain and swelling in the fractured bone, deformity, and musculoskeletal malfunction. This study aims to determine the prevalence of humerus fracture in Sanglah General Hospital Centre of April 2015 - December 2016. Methods: A retrospective descriptive cross-sectional study by secondary data was conducted among 27 medical records of the patient. The sample population of this study were all inpatients with humerus fracture at orthopaedic installation Sanglah General Hospital during April 2015December 2016. Data were analyzed using SPSS version 21 for Windows.
Results: Most cases were females (51.9\%). The age groups of $<20$ years old and $20-40$ years old have the highest frequency $(29.6 \%$, respectively). The students had the most common of humerus fracture (33.0\%). Closed fracture prevalence was found by $77,8 \%$, and the open fracture was $22,2 \%$ from all cases. Management of the most committed to a closed fracture is ORIF while the open fracture is having debridement ORIF as the most committed management.

Conclusion: The most prevalence of humerus fracture at Sanglah General Hospital during the 2015-2016 period was females, age group $<20$ and 20-40 years old, occurred in students, and closed fracture type.

Keywords: Humerus Fracture, Prevalence, Sanglah General Hospital

Cite This Article: Sari, N.K.D.D., Asmara, A.A.G.Y. 2020. Gambaran prevalensi fraktur humerus di Rumah Sakit Umum Pusat (RSUP) Sanglah, Bali, Indonesia periode tahun 2015-2016. Intisari Sains Medis 11(1): 194-197. D0I: 10.15562/ism.v11i1.533

\section{ABSTRAK}

Latar belakang: Fraktur merupakan penyebab tingginya angka kecatatan di seluruh dunia. Salah satunya fraktur humerus, sering terjadi karena cedera. Gejala klasik fraktur adalah adanya riwayat trauma, rasa nyeri dan bengkak di bagian tulang yang patah, deformitas, gangguan fungsi muskuloskletal, putusnya kontinuitas tulang dan gangguan neurovascular. Penelitian ini bertujuan untuk menentukan prevalensi fraktur humerus di RSUP Sanglah dari April 2015 - Desember 2016 Metode: Penelitian potong lintang deskriptif retrospektif dengan data sekunder dilakukan terhadap 27 catatan medis pasien. Populasi sampel penelitian ini adalah semua pasien rawat inap dengan fraktur humerus di instalasi ortopedi RSUP Sanglah selama April 2015 - Desember 2016. Data dianalisis menggunakan SPSS versi 21 untuk Windows.
Hasil: Sebagian besar kasus adalah perempuan (51,9\%). Kelompok usia <20 tahun dan 20-40 tahun memiliki frekuensi tertinggi (masing-masing 29,6\%). Para siswa memiliki proporsi fraktur humerus yang paling sering $(33,0 \%)$. Prevalensi fraktur tertutup ditemukan oleh $77,8 \%$, dan fraktur terbuka adalah $22,2 \%$ dari semua kasus. Manajemen yang paling banyak terhadap fraktur tertutup adalah ORIF sedangkan fraktur terbuka mengalami debridemen ORIF sebagai manajemen yang paling banyak.

Kesimpulan: Prevalensi fraktur humerus yang paling banyak di RSUP Sanglah selama periode 2015-2016 adalah wanita, kelompok usia $<20$ dan 20-40 tahun, terjadi pada siswa, dan tipe fraktur tertutup. \section{Bali, Indonesia} Kedokteran Universitas Udayana,

${ }^{2}$ Departemen Ortopedi dan Traumatologi, Fakultas Kedokteran Universitas Udayana, RSUP Sanglah, Bali, Indonesia

\section{*Korespondensi:}

Ni Kadek Dyah Devita Sari;

Mahasiswa Program Studi

Pendidikan Dokter, Fakultas

Kedokteran Universitas Udayana,

Bali, Indonesia;

dyahdevita30@yahoo.com

Diterima: $18-06-2019$

Disetujui: $11-03-2020$

Diterbitkan: 24-03-2020
Kata kunci: Fraktur Humerus, Prevalensi, Rumah Sakit Umum Sanglah

Cite Pasal Ini: Sari, N.K.D.D., Asmara, A.A.G.Y. 2020. Gambaran prevalensi fraktur humerus di Rumah Sakit Umum Pusat (RSUP) Sanglah, Bali, Indonesia periode tahun 2015-2016. Intisari Sains Medis 11(1): 194-197. D0I: 10.15562/ism.v11i1.533

\section{PENDAHULUAN}

Fraktur merupakan penyebab tingginya angka kecacatan di seluruh dunia. Salah satunya, fraktur humerus, sering terjadi karena cedera. ${ }^{1}$ Menurut World Health Organization (WHO), kasus fraktur terjadi di dunia kurang lebih 13 juta orang pada tahun 2008 dengan angka prevalensi sebesar $2,7 \%{ }^{2}$
Sementara pada tahun 2009 terdapat kurang lebih 18 juta orang mengalami fraktur dengan angka prevalensi 4,2\% dimana pada tahun 2010 angkanya diproyeksikan meningkat menjadi 21 juta orang dengan angka prevalensi 3,5\%. ${ }^{2}$ Terjadinya fraktur tersebut termasuk didalamnya insiden kecelakaan, 
cedera olahraga, bencana kebakaran, bencana alam dan lain sebagainya. ${ }^{3}$

Gejala klasik fraktur adalah adanya riwayat trauma, rasa nyeri dan bengkak di bagian tulang yang patah, deformitas, gangguan fungsi muskuloskeletal, putusnya kontinuitas tulang, dan gangguan neurovascular. ${ }^{4}$ Berdasarkan hasil Riset Kesehatan Dasar oleh Badan Penelitian dan Pengembangan Depkes RI tahun 2007 di Indonesia terjadi kasus fraktur yang disebabkan oleh cedera antara lain karena jatuh, kecelakaan lalu lintas dan trauma benda tajam/ tumpul terutama yang terjadi pada vertebra. ${ }^{5}$ Dari 45.987 peristiwa terjatuh mengalami fraktur sebanyak 1,775 orang (3,8\%), dari 20.829 kasus kecelakaan lalu lintas, yang mengalami fraktur adalah sebanyak 1.770 orang $(8,5 \%)$. Sedangkan dari 14.127 trauma benda tajam/tumpul, yang mengalami fraktur sebanyak 236 orang $(1,7 \%){ }^{6}$ Survey Kesehatan Nasional mencatat bahwa kasus fraktur pada tahun 2008 menunjukkan prevalensi fraktur secara nasional sekitar 27,7\%.7 Pada usia muda umumnya fraktur lebih sering terjadi karena trauma, sekitar umur 45 tahun kebawah dan sering terjadi pada laki-laki dari pada perempuan. Fraktur ini biasanya disebabkan karena olahraga, pekerjaan atau lukaluka yang disebabkan oleh kecelakaan kendaraan. WHO mencatat di tahun 2011 terdapat lebih dari 5,6 juta orang meninggal dikarenakan insiden kecelakaan dan sekitar 1,3 juta orang mengalami kecacatan fisik. ${ }^{8}$ Salah satu insiden kecelakaan yang memiliki prevalensi cukup tinggi yaitu insiden fraktur sekitar $40 \%$ dari insiden kecelakaan yang terjadi. Dari semua jenis fraktur, fraktur ekstrimitas memiliki insiden yang cukup tinggi. ${ }^{8}$ Dengan banyaknya kasus fraktur, peran Rumah Sakit juga sangat diperlukan untuk menangani kasus tersebut. Pasien dengan fraktur perlu mendapatkan pertolongan dan pelayanan kesehatan untuk meminimalkan resiko ataupun komplikasi lanjut dari fraktur. fraktur memerlukan pemberian asuhan keperawatan yang komprehensif. Asuhan terutama ditujukan untuk memenuhi kebutuhan dasar klien yang terganggu dan mencegah/mengurangi komplikasi terutama immobilisasi (nicky, 2013).

Berdasarkan data dari Departemen Kesehatan RI tahun 2011 di Indonesia didapatkan sekitar 8 juta orang mengalami kejadian fraktur dengan jenis fraktur yang berbeda dan penyebab yang berbeda. $^{7}$ Didapatkan data $25 \%$ penderita fraktur mengalami kematian, $45 \%$ mengalami cacat fisik, $15 \%$ mengalami stress psikologis karena cemas maupun depresi, dan 10\% mengalami kesembuhan dengan baik. Berdasarkan data Dinas Kesehatan RI Jawa Timur, di Indonesia khususnya di Jawa Timur pada tahun 2011 menunjukan prevalensi kasus fraktur humerus cukup tinggi yaitu $71,4 \%$ dengan rata rata laki-laki yang berusia $15-45 \%{ }^{7}$
Salah satu jenis fraktur humerus yaitu fraktur humerus proksimal (FHP) memiliki distribusi kejadian paling sering pada anak-anak dan remaja dimana menyumbang $0,5 \%$ menjadi $3,5 \%$ dari semua fraktur. ${ }^{9}$ Pada pasien yang lebih muda dari usia 18 bulan, dua pertiga dari semua patah tulang humerus mungkin terkait dengan kekerasan (abuse). Proporsi fraktur metaphyseal lebih tinggi pada pasien pra-pubertas, sedangkan proporsi epiphyseal separation lebih tinggi pada remaja. Di antara anak-anak yang lebih tua dan remaja, anak laki-laki terhitung dalam $60 \%$ dai total kasus, dan fhp terutama melibatkan lengan non-dominan. ${ }^{9}$

Berdasarkan data diatas fraktur humerus memiliki prevalensi yang tinggi dan di Indonesia masih sedikit penelitian menganai fraktur humerus, oleh karena itu pada penelitian ini, penulis ingin mengatahui gambaran kasus fraktur humerus di RS Sanglah dari tahun 2015-2016 berdasarkan beberapa variabel yang dinilai.

\section{METODE}

Jenis penelitian yang digunakan adalah penelitian deskriptif-retrospektif dengan desain potong lintang secara retrospektif, dimana peneliti melakukan pengumpulan data satu kali dengan menggunakan data rekam medis menggunakan total sampling terhadap 27 responden dengan teknik Total Sampling. Penelitian dilakukan di RSUP Sanglah Denpasar dengan pertimbangan tersedianya data penderita fraktur humerus di RSUP Sanglah Denpasar dari Bulan April 2015-Desember 2016. Adapun kriteria inklusi pada penelitian ini adalah semua pasien yang terdaftar dan terdiagnosis fraktur humerus pada rekam medis di RSUP Sanglah Denpasar. Sedangkan kriteria eksklusi adalah pasien yang tidak memiliki variabel umur, pekerjaan jenis kelamin dan diagnosis yang dicari dalam rekam medis.

Seluruh data yang diperoleh kemudian dikumpulkan dan ditabulasi dalam bentuk jumlah dan persentase. Data kemudian diolah dengan menggunakan komputer melalui analisis secara deskriptif menggunakan piranti lunak SPSS versi 21 untuk Windows dan dijabarkan secara naratif.

\section{HASIL}

Sesuai dengan Tabel 1, dapat dilihat bahwa distribusi frekuensi jenis kelamin dari sampel adalah $14(51,9 \%)$ pada wanita dan $13(48,1 \%)$ untuk jenis kelamin laki-laki. Untuk distribusi frekuensi umur, setelah dilakukan analisis ditemukan bahwa ada empat kelompok umur, yaitu $<20$ tahun, 20-40 tahun, 41-60 tahun, serta $>60$ tahun. Terdapat sebanyak delapan sampel berusia $<20$ tahun 
Tabel 1 Karakteristik responden penelitian berdasarkan data demografis

\begin{tabular}{lcc}
\hline Variabel & Jumlah (N=27) & Persentase (\%) \\
\hline Jenis kelamin & & \\
$\quad$ Perempuan & 14 & 51,9 \\
$\quad$ Laki-laki & 13 & 48,1 \\
Umur (Tahun) & & \\
$\quad<20$ & 8 & 29,6 \\
$20-40$ & 8 & 29,6 \\
$41-60$ & 7 & 25,9 \\
$>60$ & 4 & 14,8 \\
Pekerjaan & & \\
Pelajar & 9 & 33,3 \\
Pensiunan Tentara & 1 & 3,7 \\
Pedagang & 1 & 3,7 \\
Pegawai Swasta & 6 & 22,2 \\
Petani & 2 & 7,4 \\
Lain-lain & 8 & 29,6 \\
Jenis Fraktur & & 77,8 \\
Tertutup (Closed) & 21 & 22,2 \\
$\quad$ Terbuka (Open) & 6 & \\
\hline
\end{tabular}

Tabel 2 Jenis penatalaksanaan fraktur berdasarkan jenis fraktur

\begin{tabular}{lccc}
\hline & \multicolumn{2}{c}{ Diagnosis (N=27) } & \\
\cline { 2 - 3 } Penatalaksanaan & Tertutup (N=21) & Terbuka (N=6) & Total \\
\hline Bolyd Amputation + Debridement, & 1 & 1 & 2 \\
Imobilisasi, Back Slab + U Slab & & & \\
Debridemen ORIF & 0 & 4 & 4 \\
Debridemen, External Fixation & 0 & 1 & 1 \\
ORIF & 20 & 0 & 20 \\
\hline
\end{tabular}

dengan persentase sebesar $29,6 \%$, dilanjutkan dengan kelompok usia 20-40 tahun yang memiliki frekuensi sama dengan kelompok umur $<20$ tahun, tujuh orang untuk kelompok berumur 41-60 tahun $(25,6 \%)$, serta empat $(14,8 \%)$ sampel berumur $>60$ tahun.

Pada Tabel 1 pelajar ditemukan sejumlah 9 orang (33,3\%), diikuti dengan pekerjaan lainlain sebanyak 8 orang dengan presentase sebesar $(29,6 \%)$, pegawai swasta sebanyak 6 orang $(22,2 \%)$ , petani sebanyak 2 orang $(7,4 \%)$, serta pedagang dan pensiunan tentara yang memiliki proporsi masing-masing 1 dengan presentase sebesar $(3,7 \%)$.

Berdasarkan sampel yang didapat setelah mengikuti kriteria inklusi dan eksklusi dari penelitian, telah ditemukan bahwa prevalensi fraktur humerus di RSUP Sanglah periode 2015-2016 adalah 27. Prevalensi fraktur dibagi berdasarkan jenisnya seperti yang tampak pada Tabel 1. Berdasarkan jenisnya, fraktur humerus dibagi menjadi dua yaitu fraktur terbuka dan fraktur tertutup. Ditemukan sejumlah $77,8 \%$ (21 orang) dari total sampel mengalami fraktur tertutup dan $22,2 \%$ (6 orang) menderita fraktur terbuka (Tabel 1).

Berdasarkan Tabel 2, terdapat 8 jenis penatalaksanaan di RSUP Sanglah untuk kasus fraktur humerus. Penatalaksanaan ini dibagi berdasarkan deskripsi diagnosis fraktur humerus dan ditemukan sebagian besar pasien dengan fraktur tertutup mendapatkan penatalaksanaan berupa ORIF, dimana terdapat 10 kasus fraktur tertutup dengan penatalaksanaan ini. Dilanjutkan dengan ORIF CCW dengan jumlah 9, dan ORIF plate screw serta body amputation + debridemen; imobilisasi; back slab; U Slab yang berjumlah masing-masing satu untuk penatalaksanaan pada fraktur tertutup. Untuk fraktur terbuka, ditemukan 3 penatalaksanaan yang berupa debridement ORIF, dan masing-masing satu untuk debridemen + back slab, debridemen + external fixation, dan debridemen + ORIF PS (Tabel 2).

\section{PEMBAHASAN}

Pada penelitian ini, ditemukan lebih banyak sampel memiliki jenis kelamin wanita dengan jumlah 14 (51,9\%) dibanding jenis kelamin lakilaki yang berjumlah 13 (48,1\%). Hal ini serupa dengan penelitian yang dilakukan oleh Amin et al pada tahun 2014 dimana ditemukan lebih banyak sampelnya yang berjenis kelamin wanita. ${ }^{8}$ Hal ini terjadi dikarenakan oleh jenis kelamin wanita sendiri yang merupakan salah satu faktor risiko untuk mengalami fraktur humerus akibat adanya kecenderungan kurangnya aktivitas fisik, BMI yang rendah, serta adanya riwayat maternal. ${ }^{10}$

Kelompok umur $<20$ tahun dan 20-40 tahun memiliki frekuensi terbesar, diikuti dengan kelompok umur $>60$ tahun yang memiliki frekuensi paling kecil diantara semua kelompok umur. Hasil penelitian ini mengindikasikan bahwa baik kelompok usia $<20$ tahun maupun dalam rentangan 20-40 tahun memiliki kecenderungan terbesar untuk beresiko terjadinya fraktur oleh berbagai sebab. Hasil penelitian ini berbeda dengan studi terdahulu yang dilakukan oleh Ensrud KE dimana angka kejadian fraktur cenderung semakin meningkat seiring dengan bertambahnya usia. ${ }^{11}$ Akan tetapi perbedaannya bahwa penelitian sebelumnya lebih berpedoman pada fraktur dengan penyebab penuaan dimana faktor penyebab fraktur tertinggi di negara berkembang masih didominasi oleh kejadian kecelakaan.

Berdasarkan deskripsinya, fraktur tertutup memiliki prevalensi lebih banyak dibandingkan dengan fraktur terbuka dengan persentase sebesar $77,8 \%$. Fraktur terbuka merupakan trauma yang 
lebih berat dibandingkan fraktur tertutup berdasarkan keterlibatan otot dan kulit serta kemungkinan terjadi infeksi yang lebih besar. ${ }^{12}$ Didukung oleh penelitian Amin et al yang menyebutkan sejumlah $23 \%$ pasien fraktur mengalami trauma berat dan $74,2 \%$ menderita trauma ringan/sedang. ${ }^{8}$ Jenis fraktur yang terjadi juga dipengaruhi oleh lokasi, aktivitas yang dilakukan sebelum fraktur terjadi maupun jenis frakturnya seperti pada penelitian pendahuluan sebelumnya yang dilakukan terkait cedera spinal pasca aktivitas air (Water Sport). ${ }^{13}$ Berkaitan dengan hal tersebut maka resiko untuk terjadinya fraktur terbuka atau tertutup dipengaruhi banyak faktor.

\section{SIMPULAN}

Prevalensi fraktur humerus di RSUP Sanglah periode 2015-2016 menunjukkan jenis kelamin wanita cenderung lebih banyak mengalami fraktur humerus dibandingkan laki-laki. Fraktur tertutup memiliki lebih banyak proporsi dibandingkan fraktur terbuka dan penatalaksanaan terbanyak yang dilakukan untuk fraktur tertutup adalah ORIF sedangkan untuk fraktur terbuka penatalaksaan untuk fraktur terbuka terbanyak adalah debridement ORIF.

\section{KONFLIK KEPENTINGAN}

Tidak ada.

\section{ETIKA PENELITIAN}

Sebelum penelitian ini berjalan, etika penelitian telah diterima oleh Komisi Etik, Fakultas Kedokteran, Universitas Udayana, Bali, Indonesia.

\section{PENDANAAN}

Penelitian ini berjalan tanpa melibatkan pendanaan dari pihak sponsor manapun.

\section{KONTRIBUSI PENULIS}

Seluruh penulis memiliki kontribusi yang sama dalam penulisan laporan penelitian ini baik dari tahap penyusunan kerrang konsep hingga melaporkan hasil penelitian dalam bentuk publikasi.

\section{DAFTAR PUSTAKA}

1. Hariyono DC, Hasan M, Prasetyo R. Perbandingan Rentang Gerak Sendi Bahu Siku dan Kekuatan Otot Lengan Atas pada Pasien Fraktur Humerus dengan Terapi Operatif dan Non-Operatif RS Dr. Soebandi. Journal of Agromedicine and Medical Sciences. 2015;1(1):25-28

2. Amin S, Achenbach SJ, Atkinson EJ, Khosla S, Melton LJ 3rd. Trends in fracture incidence: a population-based study over 20 years. J Bone Miner Res. 2014;29(3):581-589.

3. Karladani AH, Granhed H, Kärrholm J, Styf J. The influence of fracture etiology and type on fracture healing: a review of 104 consecutive tibial shaft fractures. Arch Orthop Trauma Surg. 2001;121(6):325-328.

4. Loi F, Córdova LA, Pajarinen J, Lin TH, Yao Z, Goodman SB. Inflammation, fracture and bone repair. Bone. 2016;86:119-130.

5. Kwok AW, Leung JC, Chan AY, et al. Prevalence of vertebral fracture in Asian men and women: comparison between Hong Kong, Thailand, Indonesia and Japan. Public Health. 2012;126(6):523-531.

6. Ramadhani RP, Romadhona N, Djojosugito MA, Dyana EH, Rukanta D. Hubungan Jenis Kecelakaan dengan Tipe Fraktur pada Fraktur Tulang Panjang Ekstremitas Bawah. Jurnal Integrasi Kesehatan \& Sains. 2019;1(1):32-35

7. Riset Kesehatan Dasar. Angka Kejadian Fraktur di Indonesia. Kementerian Kesehatan Republik Indonesia. 2012.

8. Amin S, Achenbach SJ, Atkinson EJ, Khosla S, Melton LJ 3rd. Trends in fracture incidence: a population-based study over 20 years. J Bone Miner Res. 2014;29(3):581-589.

9. Lefevre Y, Journeau P, et al. 2013. Proximal humerus fractures in children and adolescents. Orthopaedics \& Traumatology: Surgery \& Research 100 (2014) S149-S156.

10. Chu SP, KelseyJL, Keegan TH, et al. Risk factors for proximal humerus fracture. Am J Epidemiol. 2004;160(4):360-367.

11. Ensrud KE. Epidemiology of fracture risk with advancing age. J Gerontol A Biol Sci Med Sci. 2013;68(10):1236-1242.

12. Tscherne H, Südkap NP. Patofyziologie otevrených zlomenin a základy jejich osetrování. (Souborný referát) [Pathophysiology of open fractures and principles of their treatment. Review]. Acta Chir Orthop Traumatol Cech. 1990;57(3):193-212.

13. Suyasa IK, Lestari AAW, Prabawa IPY, Marta KKA. Water sport-related spine injury in Bali: a review and preliminary study. Indonesia Journal of Biomedical Science. 2019;13(2):72-76.

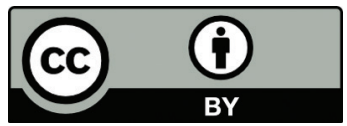

This work is licensed under a Creative Commons Attribution 